Article

\title{
Investigation of the Optimal Model for the Development of Re- newable Energy in Iran using a Robust Optimization Approach
}

\author{
Atefeh Behzadi Forough, Nima Norouzi, Maryam Fani *
}

How to cite this paper: Behzadi

Forough, A., Norouzi, N., \& Fani, M. (2021). Investigation of the Optimal Model for the Development of Renewable Energy in Iran using a Robust Optimization Approach. World Journal of Electrical and Electronic Engineering, 1(1), 1-20. Retrieved from https://www.scipublica-

tions.com/journal/index.php/wjeee/article/view/58
Received: July 1, 2021

Accepted: August 8, 2021

Published: August 9, 2021

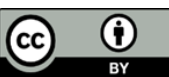

Copyright: (C) 2021 by the authors. Submitted for possible open access publication under the terms and conditions of the Creative Commons Attribution (CC BY) license (http://creativecommons.org/licenses /by/4.0/).
${ }^{1}$ Department of energy engineering and physics, Amirkabir university of technology (Tehran polytechnic), 424 Hafez Avenue, PO Box 15875-4413, Tehran, Iran

*Correspondence: mfani@aut.ac.ir

\begin{abstract}
Due to its geographical location, Iran has numerous capacities in renewable energy, and this issue has made the need to develop renewable energy on the authorities' agenda. This underscores the need to provide an optimal model for developing renewable energy. Therefore, in this study, the main purpose was to provide an optimal renewable energy model. In line with this goal, by choosing the cost function as the objective function and considering the potential constraints of renewable energy (resource constraints), the amount of electricity consumption in each of the 16 electricity regions (demand constraint) and the limitation of renewable energy production coefficient (Technical constraints), the optimal model of renewable energy use was designed and solved using a solid programming model in LINGO software. The optimal model results show 15.19\% small hydropower, $24.30 \%$ wind energy, $5.52 \%$ biomass energy, $6.13 \%$ is geothermal energy, $4.79 \%$ is tidal energy, and $44.07 \%$ solar energy. The optimum portfolio of renewable energy is estimated in this paper using the robust optimization approach. The results showed which renewable technology has the greater potential to take more share of the energy portfolio. The results of this investigation help policymakers to choose the most suitable renewable technologies to support.
\end{abstract}

Keywords: Renewable energies; Optimal model; Sustainable optimization; Linear Programming.

\section{Introduction}

Energy plays an infrastructural role in societies' economic life, which means that economic development will be possible when sufficient and timely energy is available. A look back shows that there has always been great global competition for energy resources, as national security and the Robust Optimization Approach of government systems depend largely on access to these resources[1]. Fortunately, Iran is one of the world's richest countries in diverse energy resources and reserves. These resources are offered to the consumer in our country at much lower prices than in other countries and more easily. Undoubtedly, these energy sources will run out one day. Since modern man's normal life is not possible without using energy resources, it is necessary to invest in energy efficiency methods and new technologies for energy extraction[2].

Renewable energy is a new issue in our country and the world. Also, the stages of development and progress of different renewable energy technologies are different. Some, such as wind and photovoltaic energy, have evolved to a higher degree, and some, such as solar waves and thermal power plants, are in the lower stages of development, but all need research and development to improve performance [3]. Due to the novelty of renewable energy technology, research and innovation on these systems are far more important, so that the issue of research is an integral part of renewable systems and the only way to overcome obstacles to the development and promotion of renewable energy, creating areas for research development, technology transfer, and technology modernization $[4,5]$. 
Despite the importance of renewable energy in providing clean energy, there is still no study to provide a suitable model for using and expanding this energy type in Iran. Therefore, in this study, an attempt has been made to provide an optimal model for renewable energy use $[6,7]$.

This study is organized into five sections; After the introduction, the status of renewable energy, its place and importance globally, and Iran is examined, the article's background and research method are stated. In section 3, the model is designed and solved, and in section 4, simulations are performed, and the analysis of the results is stated, and in the end, a summary and suggestions are presented.

\subsection{Renewable energy}

Fossil fuels provide more than $81 \%$ of the world's energy consumption and more than $95 \%$ of Iran's energy [8]. Iran is the second-largest OPEC member in oil production, with about 8.6 percent (12.3 billion tons) of the world's oil resources and 17 percent (26.6 trillion cubic meters) of the world's gas resources located in Iran. Iran's oil production in 2011 was about 1470 million barrels, with 4.1 million barrels per day. Gas production is 288.7 billion barrels per day, which in 1991 was about 78.8 thousand barrels per day [9]. These and other detailed statistics clearly show the rapid extraction of the country's fossil resources. On the other hand, industrialized and developed countries, which are the major consumers of energy globally, are always trying to increase the share of renewable energy in their energy basket [10].

From a political and strategic point of view, one of Iran's most important capabilities and strengths is its power in the world's fossil energy market, on which developed countries currently depend. On the other hand, global warming has reached a critical level, and other environmental issues have caused the use of fossil fuels to be subject to fundamental criticism. Hence, the global approach of the powers limits fossil energy use [10, 11].

The share of renewable energy in supplying the European continent's energy needs is about 24.5 percent. Simultaneously, a developing country like India ranks fifth in installed capacity of all renewable energy and fourth in installed wind farms' installed capacity [12]. Iran's share so far is $900 \mathrm{MW}$ of production capacity and mainly solar PV and wind turbines, and if we consider medium and large hydropower plants as renewable resources, this capacity will reach $7700 \mathrm{MW}$ [13].

According to the announcement of the New Energy Organization of Iran, "reduction of environmental pollution," "reduction of fossil reserves," "economic savings," "promotion of security of energy supply," "distributed generation and reduction of reliance on global energy transmission networks" "Employment and development in remote areas" and "Solving the problem of urban waste" can be cited as reasons for the need to use renewable energy [14].

\subsection{Renewable energies in Iran}

During 2018, 905 MW renewable energy capacity (small water, wind, solar, and biogas) was used to generate electricity in Iran, and small hydropower plants, wind, solar, and biogas were 105.93, 306.6, 405, and 10.53 MW, respectively. Regarding geothermal energy, two power plants are under construction in Ardabil province, operational by the end of 2022. In connection with the use of wave energy, a plan has not yet been developed concerning exploiting the existing potential in our country [15].

Solar energy: At present, according to the latest statistics published by the Ministry of Energy in 2019, a total of 720,000,000 kilowatt-hours of solar electricity has been produced in the country by 406 MW photovoltaic projects, Yazd Darbid and Semnan and Tabriz solar power plants [16]. 
Biomass energy: According to the latest information published by the Ministry of Energy, two biomass power plants in two regions of Shiraz and Mashhad, with a capacity of 10 and $0.6 \mathrm{MW}$ in 2019, respectively, have been put into operation. The practical power of these two power plants is equal to 10000 and $600 \mathrm{~kW}$, respectively [17].

Small hydropower: Currently, $0.64 \%$ of the total capacity of hydropower plants in operation belongs to small hydropower plants, and the share of specific production of these power plants, including $44,271 \mathrm{GWh}$ per year, is $0.61 \%$ [18].

Wind energy: According to the latest information in the energy balance sheet of the Ministry of Energy in 2019, with a total of 431 wind turbines in the provinces of Gilan, Khorasan, East Azerbaijan, and Sistan and Baluchestan, wind energy capacity in the country is $340,550 \mathrm{~kW}$, with a typical production of $2667 \mathrm{GWh}$ [19].

Geothermal energy: Currently, the Ministry of Energy is implementing two projects: constructing the Meshkinshahr geothermal power plant and constructing an 80-500 MW package. These two projects' design capacity is about $187 \mathrm{MW}$ in total, and their annual production is estimated at 1530 million $\mathrm{kWh}$ [20].

\subsection{Literature Review}

Regarding the use of renewable energy, no internal study has been conducted on optimizing this type of energy composition. However, in this field, various studies have been conducted around the world using linear programming and robust programming techniques, including the following:

In a study, have provided an optimal model for the development of renewable energy regions in the Eastern United States[21]. Other researchers, in their study, examined the potential of renewable energy and identified areas of Australia that have the potential to produce renewable energy, especially solar and wind energy. They proposed an optimal hybrid model for developing wind energy prospects in a region of Australia, taking into account production costs, energy costs, emission reduction costs[22]. An article studied the imbalance between energy supply and consumption; Finally, they studied the Greek energy system[23]. This study's ultimate goal was to provide an optimal model to meet Greece's energy needs concerning renewable energy sources and focus on the potential of energy production from municipal solid waste (MSW) in each region. In a study researchers examined the integration of CCS technology, emissions trading, and fuel price volatility for sustainable energy planning using a robust optimization approach[24]. In a study, a technique for planning power systems at the regional scale and carbon dioxide management" of the basis-based optimization method for planning energy systems and carbon dioxide trade in the framework of parametric-base combinations optimization has been used in conditions of uncertainty[25]. In a study researchers used the robust optimization technique for planning energy systems and the management of $\mathrm{CO}_{2}$ emissions in China by combining two parametric programming techniques - baseline and robust optimization[26]. In a study using a robust optimization approach designed a model to respond to electricity demand assuming a correlation of price information[27]. In a study, have proposed a method to provide the energy supply curve of centralized solar power plants. They used a solid linear programming model to present the studied power plant's power supply curve and maximized the profit objective function in this study[28]. In a study designed a model for the Philippine energy sector using robust planning techniques concerning non-operational constraints[29]. Other researchers, in a study, examined the role of government policies in optimizing renewable energy development in the southern Appalachian Mountains. This research presents a comprehensive system for energy planning, and their main goal in this system is to supply electricity from renewable energy sources[30]. Other authors, in their study using integer programming technique, have provided an optimal model for electricity generation intending to reduce carbon dioxide. This study showed that to reduce carbon dioxide emissions by $50 \%$ from the current level, an optimal model of the combined gas cycle, natural gas combined cycle, nuclear energy, 
and biomass energy from landfills has been selected[31]. A research studied designed a model for planning energy systems under uncertain conditions[32]. In a study, researchers designed a comprehensive system for renewable energy management. This study has used a two-stage planning model with base parameters to provide a model to support and support large-scale renewable energy management[33]. A research studied the dynamic programming technique, presented a model for managing Gasoline and greenhouse gas emissions and sustainable development of energy management in Tehran[34].

\section{Methods and Materials}

Mathematical programming is one of the optimization methods. Optimization, the art and science of allocating resources limited to the best possible situation, and linear programming is a subset of mathematical planning[35]. The answer that results from solving a linear programming problem is usually: a specific program or plan that includes the optimal values of selected activities [36].

\subsection{Robust Optimization Approach}

The robust Optimization Approach means that the model's output should not be too sensitive to the model's parameters and inputs [37]. In other words, "firmness" or "firmness" is an attribute that refers to the capacity to stabilize vague estimates or uncertain points to prevent the adverse effects of degradation of properties that are desired and should be maintained [38]. Uncertainties often justify decision-making issues due to inaccuracies, constant variability, and the inability to see future events. Many authors have researched solid arguments, and their results have led to a wide range of research [39]. The discussion of model robustness is one of the most important issues in "ethics in modeling" and, consequently, "ethics in operations research." If the models are solid, the risk of misuse or misuse will be much lower[40].

Historically, uncertain optimization began in the late 1950s and developed rapidly in both theory and algorithms. Many approaches have been used to optimize uncertain situations, including minimizing mathematical hope, minimizing deviations from ideals, and minimizing maximum costs caused by all of these approaches to face problems [41].

But the approach developed in recent years to deal with data uncertainty is robust optimization, which deals with optimization when the worst happens and may lead to a goal-minimization function. In this approach, we look for near-optimal answers that are likely to be justified[42]. In other words, by neglecting the optimality of the objective function a little, we guarantee the justification of the obtained result. Of course, regarding the uncertainty in the coefficients of the objective function, by slightly deviating from the value of the optimal objective function, we are looking for an answer that with a high probability of real answers is better than that answer [43].

In general, it is assumed that the input data is equivalent to the nominal values in mathematical programming. This attitude does not consider the effect of uncertainty on the quality and justification of the model[44]. Data that take values that are different from their nominal values may lead to several constraints being violated, and the optimal answer may not be optimized for a long time, or even its validity may be lost[45]. This argument raises the natural urge to design and provide solution methods that protect against data uncertainty, and these methods are called "robust solutions" [46].

The first step in this direction was presented by Ben-Tal [47], who proposed a linear programming model to generate an answer that is justified for all data belonging to a convex set. The above model provides highly conservative solutions (highly conservative) concerning the optimality of the nominal problem to ensure consistency, meaning that in this approach, a large amount of optimization is required to ensure the Robust Optimization Approach of the solution. The nominal issue goes away. Each input data can take any interval value [48-51]. After this, other important steps have been taken independently in 
the development of the theory of robust optimization by study[52-55]. In general, robust models are divided into two general categories: robust planning models with base data and robust scenario models. Stable programming models with their base data are divided into three mathematical models: "Stable model of Schwester", "Stable model of Ben Tal and Nemirovsky" and "Bertsims and Sim model," which "Bertsims and Sim" model is considered in this study[56].

\subsection{Bertsims and Sim model}

In robust optimization topics, a robust model called a robust counterpart is presented for each nominal problem (problem containing uncertain parameters). In other words, solid answers to the main problem are provided by solving a solid counterpart model. The nominal complex integer programming problem (equation 1 ) is considered with $n$ variables, the first $\mathrm{k}$ of integer variables[57-59].

$$
\begin{aligned}
& \text { Minimize }\left(c^{\prime} x\right) \\
& \text { subject }(A x \leq b) \\
& 1 \leq x \leq u \\
& x_{i \in Z, i=1, \ldots, k}
\end{aligned}
$$

Without losing the whole problem, it is assumed that matrices A and c contain indeterminate data, and vector $\mathrm{b}$ contains definite numbers. Assuming that each coefficient $\left(j \in N, a_{i j}\right)$ is modeled as an independent random variable with asymmetric and finite distribution $\left(j \in N, \widehat{a}_{i j}\right)$ that takes a value in the range $\left[a_{i j}-\widehat{a}_{i j}, a_{i j}+\widehat{a}_{i j}\right]$. Each $j \in N, c_{i j}$ takes a value in the interval $\left[c_{j}-d_{j}, c_{j}+d_{j}\right]$, so that dj indicates a deviation from the nominal cost factor $\mathrm{c}_{j}[60]$. Also, the only assumption for aij coefficient's distribution is its symmetry. Besides, if the number on the right fluctuates like the technical coefficients in symmetric bases, there is no disturbance in the discussion, and its solid modeling is similar to the technical coefficients[61]. To achieve the answer's stability, numbers $\left(\Gamma_{i}, i=0,1, \ldots, m\right)$ are defined that takes a value in the range $\left[0,\left|J_{i}\right|\right]$ so that it is equal to the number $\left|J_{i}\right|$ of uncertain data in the limit i. The parameter's role $\Gamma_{i}$ in constraints is to adjust the degree of stability versus the answer's conservatism level. The parameter $\Gamma_{0}$ controls the level of stability for the objective function. If $\Gamma_{0}=\left|f_{i}\right|$ so, the effect of changes in cost ratios is not fully taken into account, but all possible changes are taken into account, which is the most conservative case. The strong counterpart of Bertsimis and Sim for equation (1) is in the form of equation (2) [62-66]: 


$$
\begin{aligned}
& \operatorname{Min}(z)=c^{\prime} x+z_{0} \Gamma_{0}+\sum_{j \in j} p_{0 j} \\
& S t: \sum_{j} a_{i j} x_{j}+z_{i} \Gamma_{i}+\sum_{j \in j i} p_{i j} \leq b_{i} ; \forall i \\
& z 0=p_{0 j} \geq d_{j} y_{\mathrm{j} ; \forall i \in J_{0}} \\
& z_{i}+p_{i j} \geq \widehat{a}_{i j} y_{\mathrm{i} ; \forall i \neq 0, j \in J_{i}} \\
& p_{i j} \geq 0 ; \forall i, j \in J_{i} \\
& y_{i j} \geq 0 ; \forall j \\
& Z_{i} \geq 0 ; \forall j \\
& -y_{i} \leq x_{j} \leq y_{i} ; \forall j \\
& l_{j} \leq x_{j} \leq u_{j} \\
& x_{i} \in Z, i=1, \ldots, k
\end{aligned}
$$

If the number on the right, $b_{i}$ be in the interval $\left[b_{i}-\widehat{b_{i}}, b_{i}+\widehat{b_{i}}\right]$, also takes a value, the solid counterpart of the Bertsmis and Sim for equation (1) will be in the form of equation (3)[67]:

\subsection{Model design}

2.3.1. General form of a nominal model of electricity generation from renewable energies

$$
\begin{aligned}
& \operatorname{Min}(z)=c^{\prime} x+z{ }_{0} \Gamma_{0}+\sum_{j \in J_{0}} p_{0 j} \\
& S . t: \sum_{j} a_{i j} x_{j}+z_{i} \Gamma_{i}+\sum_{j \in j i} p_{i j} \leq b_{i} ; \forall i \\
& z 0=p_{0 j} \geq d_{j} y_{\mathrm{j} ; \forall i \in J 0} \\
& z_{i}+p_{i j} \geq \widehat{a_{i j}} y_{\mathrm{i} ; \forall i \neq 0, j \in J_{i}} \\
& z_{i}+p_{i 0} \geq \widehat{b_{i} ; \forall i} \\
& p_{i j} \geq 0 ; \forall i, j \in J_{i} \\
& y_{i j} \geq 0 ; \forall j \\
& Z_{i} \geq 0 ; \forall j \\
& -y_{i} \leq x_{j} \leq y_{i} ; \forall j \\
& l_{j} \leq x_{j} \leq u_{j} \\
& x_{i} \in Z, i=1, \ldots, k
\end{aligned}
$$

In this section, using linear programming technique and selecting the cost function as the objective function and considering the potential limitations of renewable energy (resource constraints) [68], the amount of electricity consumption in each of the 16 electricity regions (demand constraint) and reliability limit Production of energy from renewable 
energies (technical constraints), we present the optimal pattern of use of renewable energies. It is worth noting that the use of renewable energy is possible on both large and micro scales[69]. On a micro-scale, renewable energy is used locally and sparsely. Since this model aims to provide only $10 \%$ of the country's electricity from renewable energy, this figure can be provided through micro-level exploitation, so The issue of energy exchange on a large scale and in a centralized manner has not been considered, and the issue of energy exchange has not been included in this model. As shown in Table 1 , the variables $\mathrm{X} 1$ to $\mathrm{X} 96$ represent the electricity generated from each of the renewable energies in each regional electricity[70].

Table 1. Model decision variables

\begin{tabular}{|c|c|c|c|c|c|c|}
\hline State & Tidal & Hydropower & Wind & Geothermal & Bioenergy & Solar \\
\hline Sistan & $\mathrm{X} 1$ & X17 & X33 & X49 & X65 & X81 \\
\hline Azerbaijan & $\mathrm{X} 2$ & $\mathrm{X} 18$ & X34 & $\mathrm{X} 50$ & X66 & X82 \\
\hline Bakhtar & X3 & X19 & X35 & X51 & X67 & X83 \\
\hline Fars & $\mathrm{X} 4$ & $\mathrm{X} 20$ & X36 & $\mathrm{X} 52$ & X68 & X84 \\
\hline the West & $\mathrm{X} 5$ & $\mathrm{X} 21$ & X37 & $\mathrm{X} 53$ & X69 & X85 \\
\hline Gilan & X6 & $\mathrm{X} 22$ & $\mathrm{X} 38$ & $\mathrm{X} 54$ & $\mathrm{X} 70$ & X86 \\
\hline Hormozgan & $\mathrm{X} 7$ & $\mathrm{X} 23$ & X39 & X55 & X71 & X87 \\
\hline Khorasan & $\mathrm{X} 8$ & $\mathrm{X} 24$ & $\mathrm{X} 40$ & X56 & $\mathrm{X} 72$ & X88 \\
\hline Mazandaran & X9 & $\mathrm{X} 25$ & $\mathrm{X} 41$ & $\mathrm{X} 57$ & X73 & X89 \\
\hline Semnan & $\mathrm{X} 10$ & $\mathrm{X} 26$ & $\mathrm{X} 42$ & $\mathrm{X} 58$ & X74 & X90 \\
\hline Zanjan & $\mathrm{X} 11$ & $\mathrm{X} 27$ & $\mathrm{X} 43$ & $\mathrm{X} 59$ & X75 & X91 \\
\hline Esfahan & $\mathrm{X} 12$ & $\mathrm{X} 28$ & $\mathrm{X} 44$ & X60 & X76 & X92 \\
\hline Tehran & $\mathrm{X} 13$ & $\mathrm{X} 29$ & $\mathrm{X} 45$ & X61 & X77 & X93 \\
\hline Khuzestan & $\mathrm{X} 14$ & X30 & $\mathrm{X} 46$ & X62 & X78 & X94 \\
\hline Kerman & $\mathrm{X} 15$ & X31 & $\mathrm{X} 47$ & X63 & X79 & X95 \\
\hline Yazd & X16 & X32 & X48 & X64 & X80 & X96 \\
\hline
\end{tabular}

In this model, to obtain the optimal pattern of renewable energy use from the cost of electricity generation function in line with the minimum cost of electricity generation from renewable energy, including; Solar energy, biomass energy, geothermal energy, wind energy, small hydropower energy, and tidal energy have been used (equation 4)[71].

$$
\operatorname{Min}\left(A \sum_{i=1}^{16} x_{i}+B \sum_{x=17}^{32} x_{i}+C \sum_{x=33}^{48} x_{i}+D \sum_{x=34}^{64} x_{i}+E \sum_{x=65}^{80} x_{i}+F \sum_{x=81}^{96} x_{i}\right)
$$

In this model, the objective function's coefficients include the cost of generating electricity from solar energy, biomass, geothermal, wind, small hydropower, and tidal[72]. Because the equipment and technology for using renewable energy in our country are often imported, so the cost of generating electricity from renewable energy in the 16 regional electricity regions in the country is considered the same. Table 2 shows the average cost of generating a one-kilowatt hour of electricity from each renewable energy source[73]. 
Table 2. Cost of a unit of electricity generation from various types of renewable energy $(\$ / \mathrm{kWh})$

\begin{tabular}{cc}
\hline Renewable energy & Cost $(\$ \mathbf{k W h})$ \\
\hline Solar Energy & 0.059 \\
Biomass energy & 0.088 \\
Geothermal energy & 0.078 \\
Wind energy & 0.064 \\
Hydropower & 0.053 \\
Tidal energy & 0.064 \\
\hline
\end{tabular}

Renewable energy potential constraints in the whole country: One of the most important constraints considered in this model has been the constraint of renewable energy potential. Based on the calculations, the potential of solar energy, biomass, geothermal, wind, small hydropower, and tidal can be considered according to the values according to Table 3 [74].

Table 3. Values to the right of the potential constraint.

\begin{tabular}{ccc}
\hline renewable energy & $\begin{array}{c}\text { renewable energy potential } \\
\text { [TWh] }\end{array}$ & Variable \\
\hline Solar Energy & 193161 & $\mathrm{R} 1$ \\
Biomass energy & 196.2 & $\mathrm{R} 2$ \\
Geothermal energy & 24.7 & $\mathrm{R} 3$ \\
wind energy & 265.9 & $\mathrm{R} 4$ \\
Hydropower & 12.2 & $\mathrm{R} 5$ \\
Tidal energy & 26.1 & $\mathrm{R} 6$ \\
\hline
\end{tabular}

$$
\begin{aligned}
& \sum_{i=1}^{16} x_{i} \leq R_{1} \\
& \sum_{x=17}^{32} x_{i} \leq R_{2} \\
& \sum_{x=33}^{48} x_{i} \leq R_{3} \\
& \sum_{x=34}^{64} x_{i} \leq R_{4} \\
& \sum_{x=65}^{80} x_{i} \leq R_{5} \\
& \sum_{x=81}^{96} x_{i} \leq R_{6}
\end{aligned}
$$

Renewable energy potential limit per regional electricity: The values to the right of the renewable energy potential limit in each regional electricity, which includes the values $R_{8}$ to $R_{102}$, are given in Table 4 for the renewable energy potential each regional electricity[75].

$$
x_{i} \leq R_{i+6 ;}=1, \ldots, 96
$$


Table 4. Renewable energy potential in different regional distribution electricity (GWh)

\begin{tabular}{ccccccc}
\hline & Tidal & Hydro & Wind & $\begin{array}{c}\text { Geo- } \\
\text { thermal }\end{array}$ & Bio & Solar \\
\hline Sistan & 6308.358 & 0 & 35798.616 & 1716.96 & 3903.732 & 22897917.56 \\
Azarbayjan & 0 & 850.15 & 8936.718 & 7082.46 & 29264.662 & 9452557.66 \\
Bakhtar & 0 & 299.782 & 532.238 & 0 & 17150.98 & 8335888.82 \\
Fars & 1521.9792 & 207.662 & 15873.256 & 3433.92 & 18230.058 & 19000955.4 \\
West & 0 & 1717.646 & 6593.048 & 0 & 14631.204 & 8079242.5 \\
Gilan & 1736.756 & 3347.974 & 29033.774 & 0 & 10310.09 & 711376.12 \\
Hormoz & 8382.038 & 0 & 14482.538 & 1716.96 & 2116.31 & 9088987.46 \\
Khorasan & 0 & 23.324 & 69931.722 & 1716.96 & 20545.406 & 25746275.8 \\
Mazanda- & 2617.384 & 2019.878 & 2858.66 & 1716.96 & 19663.896 & 2896295.92 \\
ran & & & & & & \\
Semnan & 0 & 52.038 & 61458.544 & 0 & 1925.798 & 11765191.06 \\
Zanjan & 0 & 373.38 & 15143.548 & 0 & 5270.146 & 3490300.38 \\
Esfhan & 0 & 1180.312 & 0 & 3433.92 & 11676.896 & 15391203.8 \\
Tehran & 0 & 598.878 & 0 & 1716.96 & 13513.612 & 3644326 \\
Khuzestan & 5013.386 & 1442.952 & 0 & 0 & 16390.01 & 8562267.84 \\
Kerman & 0 & 0 & 0 & 0 & 6247.402 & 23934565.48 \\
Yazd & 0 & 0 & 0 & 1716.96 & 1437.464 & 16300428.2 \\
Total & 25579.0192 & 12113.976 & 260642.662 & 24252.06 & 192277.666 & 189297780 \\
\hline
\end{tabular}

Maximum power consumption limit in each of the 16 electricity regions: the values to the right of the regional power consumption limit ( $R_{103}$ to $R_{118}$ ) as the maximum amount of electricity use in each of the 16 electricity regions based on the latest statistics and information in the energy balance in 2010 and with Considering the assumption of $10 \%$ of electricity generation from renewable energy is considered[76].

$$
\begin{aligned}
& x_{1}+x_{17}+x_{33}+x_{49}+x_{65}+x_{81} \geq R_{103} \\
& x_{2}+x_{18}+x_{34}+x_{50}+x_{66}+x_{82} \geq R_{104} \\
& \vdots \\
& x_{16}+x_{32}+x_{48}+x_{64}+x_{80}+x_{96} \geq_{118}
\end{aligned}
$$

Reliability limits in each type of renewable energy: Constraints related to reliability are presented to estimate the optimal pattern of reliable electricity supply from renewable energy $[77,78]$. These coefficients are 0.1 per 10,000 hours for solar and geothermal energy, 0.5 per 10,000 hours for wind and tidal energy, 0.2 per 10,000 hours for biomass energy, and 0.67 per 10,000 hours for hydropower[79]. 


$$
\begin{aligned}
& 10 \sum_{i=1}^{16} x_{i} \leq R_{1} \\
& 5 \sum_{x=17}^{32} x_{i} \leq R_{2} \\
& 10 \sum_{x=33}^{48} x_{i} \leq R_{3} \\
& 2 \sum_{x=34}^{64} x_{i} \leq R_{4} \\
& 1.5 \sum_{x=65}^{80} x_{i} \leq R_{5} \\
& 2 \sum_{x=81}^{96} x_{i} \leq R_{6}
\end{aligned}
$$

Implicit constraint: Finally, the constraint on the non-negative nature of the model decision variables, or in other words, the implicit constraint, is presented[80].

$$
x_{i} \geq 0 ; i=1, \ldots, 96
$$

\subsubsection{Stable counterpart of the renewable energy use model}

In this study, the Bertsims and Sims model has been used to stabilize and provide a stable counterpart model. In this model, uncertainty in the objective function coefficients (cost parameters) is considered[81-83].

$$
\begin{aligned}
& P_{0+} Q_{i} \geq e A y_{\mathrm{i}} ; \mathrm{i}=1, \ldots, 16 \\
& P_{0+} Q_{i} \geq e B y_{\mathrm{i}} ; \mathrm{i}=17, \ldots, 32 \\
& P_{0+} Q_{i} \geq e C y_{\mathrm{i}} ; \mathrm{i}=33, \ldots, 48 \\
& P_{0+} Q_{i} \geq e D y_{\mathrm{i}} ; \mathrm{i}=49, \ldots, 64 \\
& P_{0+} Q_{i} \geq e E y_{\mathrm{i}} ; \mathrm{i}=65, \ldots, 80 \\
& P_{0+} Q_{i} \geq e F y_{\mathrm{i}} ; \mathrm{i}=81, \ldots, 96 \\
& -\mathrm{y}_{\mathrm{i}} \leq \mathrm{x}_{\mathrm{i}} \leq \mathrm{y}_{\mathrm{i}} ; \mathrm{i}=1, \ldots, 16 \\
& \mathrm{x}_{\mathrm{i}}, \mathrm{Q}_{\mathrm{i}} \geq 0 ; \mathrm{i}=1, \ldots, 16
\end{aligned}
$$

The conservatism level is related to cost parameters $\Gamma_{0}$, and e is the percentage of deviation in the objective function coefficients (uncertain cost parameters). After consulting with experts, professors, and experts of the New Energy Organization of Iran, this number is considered a maximum of $20 \%$. Also, $\mathrm{P}_{0}, \mathrm{Q}_{\mathrm{i}}$, and $\mathrm{y}_{\mathrm{i}}$ are stable variables that have been added to the model. It should be noted that the limitations of 29 to 35 include the constraints that are added to the model while converting the original model to a stable counterpart[84].

\section{Results and Discussion}

The model was programmed in the collection space in Lingo Link software with Excel to increase computational efficiency. Model input data were called from Excel, and the model was solved. Due to the high number of indefinite parameters in the designed model (96 indefinite parameters in the model's objective function) [85], the number of protection levels was considered bases on consultation with professors. In total, 13 levels of protection were considered. For each case, the protection level of a model is solved. The number of parameters of different protection levels is the number given in Table 5 [86]. 
Table 5. Reliability levels of stability parameters of models

\begin{tabular}{cccccccccccccc}
\hline \multicolumn{11}{c}{ Parameters } \\
\hline $\begin{array}{c}\text { Different Levels } \\
\begin{array}{c}\text { Level of cost parameter } \\
\text { Reliability }\end{array}\end{array} 1$ & 2 & 3 & 4 & 5 & 6 & 7 & 8 & 9 & 10 & 11 & 12 & 13 \\
\hline
\end{tabular}

To examine the number of constraints and variables of a stable counterpart problem, we assume that the number $\mathrm{k}$ of the nominal matrix $\mathrm{A}$ has uncertainty. If the main nominal problem has $m$ constraint and $n$ variables, it has $m+n+k$ constraint and $n+k+1$ variable according to the Bertsims model and Sim. Table 6 presents the model statistics, including the number of main constraints, number of constraint constraints, number of main variables, and number of constraint variables[87].

Table 6. Statistics of the variables

\begin{tabular}{cc}
\hline Parameter & Number \\
\hline The main limitations & 134 \\
Stability constraints & 196 \\
Main variables & 96 \\
Stability variables & 194 \\
\hline
\end{tabular}

\subsection{Model Simulation}

Table (7) presents the answers obtained from solving the model at different levels of protection. In other words, first, the values of the objective function and the deviation from the optimal are presented, and then the optimal solutions of the variables are presented.

According to the information in Table 7, with increasing protection level, the amount of deviation from the optimum and also the objective function worsens, which is fully consistent with the mathematical logic of model stabilization, so that the more uncertainty the decision-maker considers for the model, the more conservative the answers will receive. This increase in conservatism in the cost objective function will mean higher costs[88].

It is clear that as the level of protection increases, the amount of deviation from the optimal gets worse. In other words, the value of the minimum objective function increases. The higher the level of protection, the more strictly the model chooses the values of the variables in the allowable range, and ultimately the worse the response of the objective function, so changing the level of conservatism can have a significant effect on the decision maker's income. The level of protection is so significant that the decision-maker makes a sensible decision by balancing the level of risk with the extent to which the goals have been achieved[89]. 
Table 7. The values of the objective function of the stable counterpart of the model in different states of the protection level

\begin{tabular}{ccc}
\hline $\begin{array}{c}\text { Deviation from the opti- } \\
\text { mal }\end{array}$ & $\begin{array}{c}\text { Optimal values of objective func- } \\
\text { tion [M\$] }\end{array}$ & Reliability level \\
\hline 0.00000 & 2675.4 & 0 \\
0.10584 & 2979.2 & 8 \\
0.15288 & 3106.6 & 16 \\
0.18326 & 3292.8 & 24 \\
0.19502 & 3214.4 & 32 \\
0.19600 & 3224.2 & 40 \\
0.19600 & 3224.2 & 48 \\
0.19600 & 3224.2 & 56 \\
0.19600 & 3224.2 & 64 \\
0.19600 & 3224.2 & 72 \\
0.19600 & 3224.2 & 80 \\
0.19600 & 3224.2 & 88 \\
0.19600 & 3224.2 & 96 \\
\hline
\end{tabular}

In this study, according to Table 8 and the model simulation results, which are summarized in Table 9 and is a reduction in decision risk due to increasing levels of protection. Also, in consultation with professors, protection level 8 is considered to analyze the results.

Table 8. Results for the variable parameters

\begin{tabular}{lccccccc}
\hline X1 & $\mathbf{0}$ & X25 & $\mathbf{0}$ & X49 & 335301 & X73 & $\mathbf{8 5 6 5 6 1}$ \\
\hline X2 & 0 & X26 & 0 & X50 & 210273 & X74 & 533174 \\
X3 & 0 & X27 & 0 & X51 & 54315 & X75 & 381069 \\
X4 & 0 & X28 & 522297 & X52 & 576338 & X76 & 1204479 \\
X5 & 0 & X29 & 1088436 & X53 & 0 & X77 & 611137 \\
X6 & 0 & X30 & 0 & X54 & 0 & X78 & 1472499 \\
X7 & 0 & X31 & 637499 & X55 & 228209 & X79 & 0 \\
X8 & 0 & X32 & 0 & X56 & 1509580 & X80 & - \\
X9 & 0 & X33 & 0 & X57 & 0 & X81 & 0 \\
X10 & 0 & X34 & 0 & X58 & 199089 & X82 & 0 \\
X11 & 0 & X35 & 0 & X59 & 244199 & X83 & 0 \\
X12 & 0 & X36 & 0 & X60 & 0 & X84 & 715879 \\
X13 & 0 & X37 & 0 & X61 & 0 & X85 & 0 \\
X14 & 0 & X38 & 0 & X62 & 0 & X86 & 0 \\
X15 & 181513 & X39 & 0 & X63 & 0 & X87 & 715879 \\
X16 & 0 & X40 & 0 & X64 & 0 & X88 & 0 \\
X17 & 0 & X41 & 0 & X65 & 0 & X89 & 0 \\
X18 & 0 & X42 & 0 & X66 & 867547 & X90 & 0 \\
X19 & 915240 & X43 & 0 & X67 & 305988 & X91 & 0 \\
X20 & 0 & X44 & 250078 & X68 & 211940 & X92 & 0 \\
X21 & 0 & X45 & 1752001 & X69 & 535517 & X93 & 0 \\
X22 & 0 & X46 & 0 & X70 & 404309 & X94 & 877763 \\
X23 & 0 & X47 & 0 & X71 & 0 & X95 & 0 \\
X24 & 0 & X48 & 472621 & X72 & 23878 & X96 & 0 \\
\hline
\end{tabular}


In classical linear programming models, the sensitivity analysis technique was used to test the results' validation. In the robust planning method, the simulation method is used to test the results' validation, a simple expression of simulation that produces repetitions of realities in nature. In some cases, iterations of a natural reality are difficult or impossible, so simulation is an efficient tool for engineers and designers to generate iterations of phenomena at a low cost.

\subsection{Monte Carlo simulation}

One suitable simulation method is the Monte Carlo method (MCS), which has many applications in various sciences. In the discussion of uncertainty analysis, the Monte Carlo simulation method is of particular importance and interest to researchers. Today, the Monte Carlo method is used in stochastic process analysis and certain systems. In simulation practice, modeling a system's behavior during the simulation period can predict the system's actual performance. In other words, in the simulation method, modeling the system's behavior artificially during the simulation, the system's performance can be evaluated. In this paper, to achieve the degree of violation of the objective function in each case, the values of the variables obtained from each model solution were considered constant. Uncertain parameters in the considered interval were randomly generated and simulated in a uniform distribution function 10,000 times. The simulation operation of the Burtsims and wire solid model will occur in reverse of the model solution so that in the simulation operation, the values of the variables obtained from the solution of the model are assumed to be constant. The values of uncertain parameters are randomly generated in a uniform distribution. The general method of this simulation is: the objective function and its value are considered, the number of deterioration states of the objective function is considered, and it is assigned the number one. Otherwise, the value is considered zero, so each time Simulation The number of deterioration states of the objective function is determined. In short, for the designed model, the simulation operation is performed once for the definite model and with a different number of protection levels in the stable model (96 times).

\subsubsection{Simulation of the definite model with uncertain parameters}

To show the necessity of solidifying the designed model, we simulated the definite model to see if the definite model is used and the uncertain parameters change in their oscillation range. What is the probability of the answer getting worse and thus the model and results being unjustified? There is a result. For this purpose, the definitive model was simulated 10,000 times. The results showed that in $50.18 \%$ of cases, the answer is likely to worsen. Thus, it is necessary to solidify the model to use solidity issues' mathematical logic and decrease decision risk (probability of model violation).

\subsubsection{Simulation of a solid model with uncertain parameters}

The robust model operates so that the level of decision risk decreases to increase the level of protection. In this section, to prove the correct stabilization and provide information about how the balance between the level of risk in different levels of protection, the stable model was simulated. Table 9 shows 10,000 simulations of the robust model with uncertain parameters performed for each protection level. 
Table 9. Results of 10000 times model robust simulation per protection level (percentage)

\begin{tabular}{cccc}
\hline $\begin{array}{c}\text { The answer is likely to get } \\
\text { worse }\end{array}$ & $\begin{array}{c}\text { Reliability } \\
\text { level }\end{array}$ & $\begin{array}{c}\text { The answer is likely to get } \\
\text { wors }\end{array}$ & $\begin{array}{c}\text { Reliabil- } \\
\text { ity level }\end{array}$ \\
\hline 0.1485 & 13 & 49.4109 & 0 \\
0.1188 & 14 & 36.5013 & 1 \\
0.0396 & 15 & 25.344 & 2 \\
0.0297 & 16 & 17.0676 & 3 \\
0.0297 & 17 & 10.9098 & 4 \\
0.0099 & 18 & 6.7716 & 5 \\
0 & 19 & 4.9599 & 6 \\
0 & 20 & 3.2175 & 7 \\
0 & 21 & 1.8117 & 8 \\
0 & 22 & 1.4751 & 9 \\
0 & 23 & 0.9009 & 10 \\
0 & 24 & 0.5643 & 11 \\
-- & -- & 0.2079 & 12 \\
\hline
\end{tabular}

\subsection{Discussion}

According to the results of the optimal model of renewable energy use, which is designed according to the goal of the sixth Development Plan - assuming the production of $10 \%$ of grid electricity - the largest share is related to the production of energy from small hydropower with $15.19 \%$. Then electricity generation from energy Wind, biomass, geothermal, tidal, and solar is $24.30,5.52,6.13,4.79$, and 44.07 percent.

The optimal values are equivalent to $56.04 \%$ of the total potential of small hydropower, $1.26 \%$ of the country's wind potential, $1.61 \%$ of the country's biomass potential, $10 \%$ of the country's geothermal potential, and $8.84 \%$ of the country's tidal potential.

This $10 \%$ of renewable electricity generation includes only $3.4 \%$ of the total potential of these energies in the country (excluding the potential of solar energy), which is equivalent to 10.5 million barrels of crude oil per year, which means saving 10.5 million barrels of crude and free oil-increasing this number to sell and earn more government. Also, considering the average of 678 grams of carbon dioxide production per kilowatt-hour of electricity, this amount of renewable energy production means a reduction of 12.48 million tons of $\mathrm{CO}_{2}$ pollutants.

On the other hand, due to the very high potential that the country has in receiving solar energy, this model's results show only one percent share of solar energy use. This model result is due to the high cost of technology, equipment, and technology of using solar energy in our country, which has caused the cost of producing one megawatt of solar electricity compared to other energies. Therefore, it is necessary to develop the use of renewable energy and especially solar energy as a representative of this group of energies due to the very high potential in the country, paving the way for industry growth to localize photovoltaic equipment and solar power plants to reduce electricity generation costs from this energy source(see Table 10). 
Table 10. Share of optimal amounts of renewable energy from $10 \%$ of electricity consumption in each region (percentage)

\begin{tabular}{ccccccc}
\hline Regional electricity & Tidal & Hydro & Wind & Geothermal & Bioenergy & Solar \\
\hline Sistan & 0 & 0 & 99 & 0 & 0 & 0 \\
Azerbaijan & 0 & 79.6851 & 19.305 & 0 & 0 & 0 \\
Bakhtar & 0 & 23.7402 & 4.2075 & 0 & 71.0325 & 0 \\
Fars & 47.1141 & 13.9491 & 37.9269 & 0 & 0 & 0 \\
the West & 0 & 99 & 0 & 0 & 0 & 0 \\
Gilan & 0 & 99 & 0 & 0 & 0 & 0 \\
Hormozgan & 75.0618 & 0 & 23.9283 & 0 & 0 & 0 \\
Khorasan & 0 & 1.5345 & 97.4556 & 0 & 0 & 0 \\
Mazandaran & 0 & 99 & 0 & 0 & 0 & 0 \\
Semnan & 0 & 20.8593 & 78.1308 & 0 & 0 & 0 \\
Zanjan & 0 & 60.3306 & 38.6595 & 0 & 0 & 0 \\
Esfahan & 0 & 60.3108 & 0 & 12.5235 & 26.1558 & 0 \\
Tehran & 0 & 17.523 & 0 & 50.2425 & 31.2147 & 0 \\
Khuzestan & 36.9666 & 62.0235 & 0 & 0 & 0 & 0 \\
Kerman & 0 & 0 & 0 & 0 & 77.0517 & 21.9384 \\
Yazd & 0 & 0 & 0 & 98.2872 & 0.7029 & 0 \\
\hline
\end{tabular}

Table 11. Share of optimal amounts of renewable energy from $10 \%$ of the country's electricity consumption (percent)

\begin{tabular}{cc}
\hline Energy & Share of portfolio \\
\hline Tidal energy & 4.79 \\
Small hydropower & 15.19 \\
Wind energy & 24.30 \\
Geothermal energy & 6.13 \\
Biomass energy & 5.52 \\
Solar Energy & 44.07 \\
\hline
\end{tabular}

In the Sixth development plan, it is stipulated that by the end of 2025, $10 \%$ of the country's electricity production will be provided from renewable energies. For this purpose, the optimal model of using renewable energies has been designed according to this goal in this study(see Table 11).

Comparing the values of the optimal model of $10 \%$ renewable energy development with the status of electricity production from these energies in 2019 is shown in Table 12.

Table 12. Comparison of the output values of the optimal model and the current situation (MWinstalled capacity)

\begin{tabular}{ccc}
\hline Energy & Current Amount & Optimal Amount \\
\hline Solar & 405.1 & 4407 \\
Biomass & 10.56 & 552 \\
Geothermal & 80 & 613 \\
Wind & 302.4 & 2430 \\
Hydropower & 106 & 1519 \\
Tide & 0 & 479 \\
Share & 1.2 & 10 \\
\hline
\end{tabular}




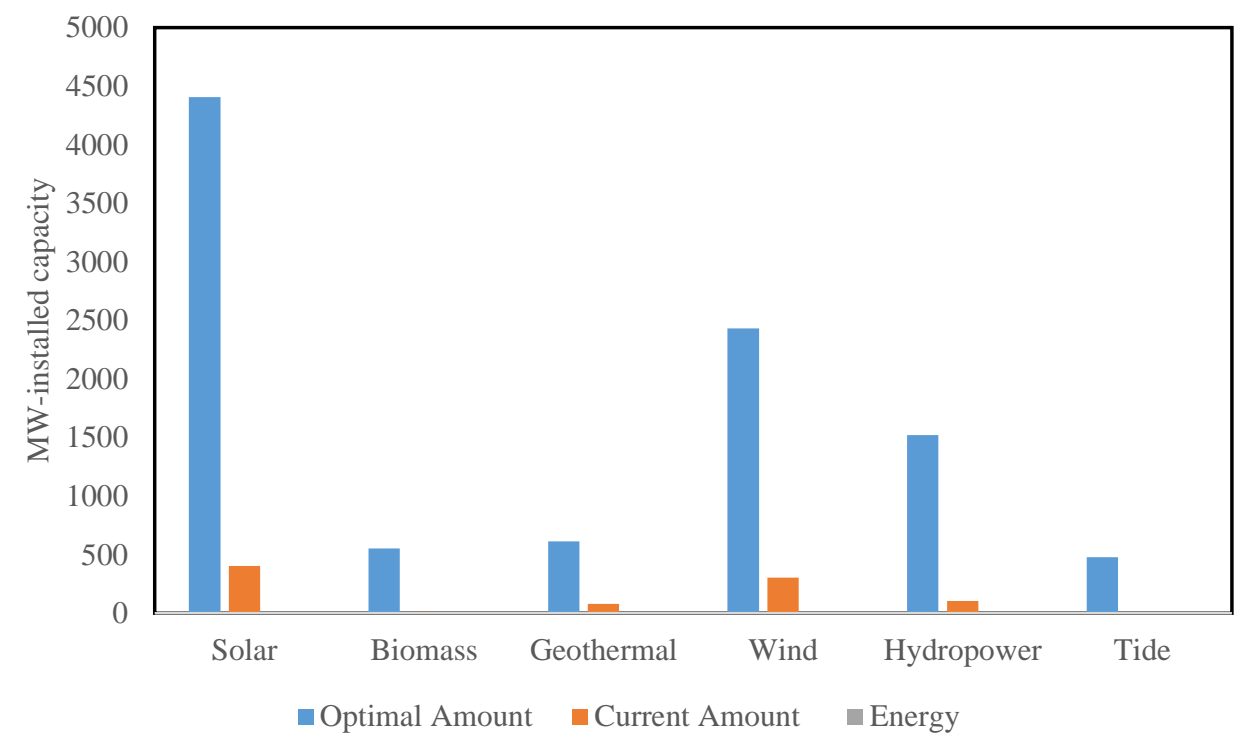

Figure 1. Current versus Optimal condition in the renewable energy installed capacity

The results of the optimal model (which is designed according to the Fourth Development Plan and shows a 10 percent share of renewable energy in the country's electricity production) show the production of 15.19 percent small hydropower, 24.30 percent wind energy, 5.52 percent biomass energy, $6.13 \%$ is geothermal energy, $4.79 \%$ is tidal energy and $44.07 \%$ solar energy. The optimal values are equivalent to $56.04 \%$ of the total small hydropower potential, $1.26 \%$ of the country's wind potential, and $1.61 \%$ of the country's biomass potential, 10 of the country's geothermal, and $8.84 \%$ of the country's tidal potential(see figure (1)).

Renewable energy is a new issue in Iran and the world, and at the same time, the stages of development and advancement of different renewable energy technologies are different $[27,28]$. If renewable energy in our country is not developed in parallel with other countries in the world, we will not have a place in the field of technical progress of this energy source, and as a result, it will cause technical and technological backwardness in this field, therefore [30]:

- The technical knowledge and technology of using renewable energy in the country should be developed as soon as possible, and the restrictions in this field should be removed, especially in the technology of using solar energy.

- The optimal combination for the medium-term development of $10 \%$ of renewable energy uses 15.19 percent small hydropower, 24.30 percent wind energy, 5.52 percent biomass energy, $6.13 \%$ is geothermal energy, $4.79 \%$ is tidal energy, and $44.07 \%$ solar energy.

- By replacing electricity generation from renewable energy, it is possible to save a significant amount of crude oil per year, which according to the current significant price of oil, this amount of oil can be exported, and a significant income can be earned from it.

- By developing the use of renewable energy sources, environmental pollution can be significantly reduced.

\section{Conclusion}

Given the growing need for energy in today's societies to meet different needs, scientists and researchers in many countries, including Iran, have fundamental approaches to achieving renewable energy on their agenda. Scientists believe that renewable and clean energy can become the first option for energy production due to the limited fossil 
fuels and environmental pollution because this type of energy is clean, cheap, and especially renewable. Due to its geographical location, Iran has numerous capacities in producing new and renewable energy, and this issue has made the need to develop renewable energy on the authorities' agenda. In European countries, by 2020, it is planned that $30 \%$ of the installed capacity of countries will be for renewable resources, while in our country, due to the existence of large oil and gas resources, the country plans to use fossil energy to produce energy if which should gradually increase the share of renewable resources, as in most parts of the world. This issue emphasizes the need for an optimal model for the development of renewable energy use. Therefore, in this study, the main purpose is to provide an optimal renewable energy model, which provides the required electricity and reduces environmental pollution.

Supplementary Materials: All required data is presented in the paper.

Author Contributions: “Conceptualization, N.N. and M.F.; methodology, A.B.; software, N.N.; validation, M.F., A.B. and M.F.; formal analysis, N.N.; investigation, N.N.; resources, N.N.; data curation, N.N.; writing - original draft preparation, M.F.; writing - review and editing, A.B.; visualization, N.N.; supervision, A.B.; project administration, M.F.; funding acquisition, A.B. All authors have read and agreed to the published version of the manuscript."

Funding: "This research received no external funding."

Data Availability Statement: Data will be available by an official request from the corresponding author.

Acknowledgments: Author(s) at this moment thank Amirkabir university of technology for its scientific supports.

Conflicts of Interest: “The authors declare no conflict of interest."

\section{References}

[1] Mohammadi, V.; Mozaffari Shamsi, H.; Asadi, F. Investigating the relationship between economic growth, energy consumption and human development in selected MENA countries (MENA). Iran. J. Energy Econ. 2019, 8, 811-850.

[2] Ministry of Energy. Energy Balance 2017; Ministry of Energy: Tehran, Iran, 2020.

[3] Mozayani, A.H.; Essari Arani, A.; Afsharian, B.; Rasouli, A. Redefinition of the Relation between Energy Consumption and Economic Growth in Iran: Markov Switching Approach. Econ. Modeling 2015, 9, 67-89.

[4] Cheratian, I.; Goltabar, S. Energy Consumption and Regional Economic Growth: The Case of Iranian Manufacturing Sector; MPRA Paper 78315; University Library of Munich: Munich, Germany, 2017.

[5] Abdouli, M.; Hammami, S. Exploring links between FDI inflows, energy consumption, and economic growth: Further evidence from MENA countries. J. Econ. Dev. 2017, 42, 95-117.

[6] Mirzaei, M.; Bekri, M. Energy consumption and CO2 emissions in Iran, 2025. Environ. Res. 2017, 154, 345-351. [PubMed]

[7] Ghaseminejad, A.A.; Hosseini, S.; Moghaddasi, R. How energy consumption is related to agricultural growth and export: An econometric analysis on Iranian data. Energy Rep. 2019, 5, 50-53.

[8] Aghaei, M.; Lawell, C.Y.C.L. Energy, economic growth, inequality, and poverty in Iran. Singap. Econ. Rev. 2020.

[9] Tugcu, C.T.; Topcu, M. Total, renewable and non-renewable energy consumption and economic growth: Revisiting the issue with an asymmetric point of view. Energy 2018, 152, 64-74.

[10] Rahman, M.M.; Velayutham, E. Renewable and non-renewable energy consumption-economic growth nexus: New evidence from South Asia. Renew. Energy 2020, 147, 399-408.

[11] Sunde, T. Energy consumption and economic growth modelling in SADC countries: An application of the VAR Granger causality analysis. Int. J. Energy Technol. Policy 2020, 16, 41-56.

[12] Aydin, M. Natural gas consumption and economic growth nexus for top 10 natural Gas-Consuming countries: A granger causality analysis in the frequency domain. Energy 2018, 165, 179-186.

[13] Rahman, M.M.; Abul Kashem, M. Carbon emissions, energy consumption and industrial growth in Bangladesh: Empirical evidence from ARDL cointegration and Granger causality analysis. Energy Policy 2017, 110, 600-608.

[14] Akadiri, S.S.; Lasisi, T.T.; Uzuner, G.; Akadiri, A.C. Examining the causal impacts of tourism, globalization, economic growth and carbon emissions in tourism island territories: Bootstrap panel Granger causality analysis. Curr. Issues Tour. 2020, 23, 470484 .

[15] Al-Mulali, U.; Solarin, S.A.; Ozturk, I. Biofuel energy consumption-economic growth relationship: An empirical investigation of Brazil. Biofuels Bio-Prod. Biorefining 2016, 10, 753-775. 
[16] Engle, R.F.; Granger, C.W.J. Co-integration and error correction: Representation, estimation, and testing. J. Econom. 1987, 55, 251-276.

[17] Mollahosseinia, A.; Hosseinib, S.A.; Jabbaric, M.; Figolid, A.; Rahimpour, A. Renewable energy management and market in Iran: A holistic review on current state and future demands. Renew. Sustain. Energy Rev. 2017, 88, 774-788.

[18] Alamdari, P.; Mirhosseini, O.N.M. Assessment of wind energy in Iran: A review. Renew. Sustain. Energy Rev. 2012, 16, 836860.

[19] Najafi, G.; Ghobadian, B.; Mamat, B.; Yusaf, T.; Azmi, W.H. Solar energy in Iran: Current state and outlook. Renew. Sustain. Energy Rev. 2015, 49, 931-942.

[20] Ghasemi, A.; Taklif, A.; Mohammadi, T.; Mohammadian, F. Analysis of Iran's energy strategies on the horizon of 2041 in the framework of global energy scenarios. Iran. J. Energy Econ. 2017, 6, 121-189.

[21] Central Bank of Iran. National Accounts; Central Bank of Iran: Tehran, Iran, 2020.

[22] Vice President of Legal Affairs. Resolution of the High Energy Council Regarding the National Document of the Country's Energy Strategy; Vice President of Legal Affairs: Tehran, Iran, 2016.

[23] Ghaedizadeh, N.; Khalili Dizaji, H. Status of Iran's Common Oil and Gas Reservoirs from the Perspective of International Law. Mon. Oil Gas Explor. Prod. 2014, 110, 3-8.

[24] National Iranian Oil Company. Supply of 6 Million Barrels of Crude Oil and Gas Condensate in the Energy Exchange; National Iranian Oil Company: Tehran, Iran, 2019; Available online: https://www.nioc.ir/portal/home/?news/100193/359783/360628/ (accessed on 25 June 2021).

[25] Dudlák, T. After the sanctions: Policy challenges in transition to a new political economy of the Iranian oil and gas sectors. Energy Policy 2018, 121, 464-475.

[26] Ministry of Energy. Energy Statistics and Charts of Iran and the World 2017; Ministry of Energy: Tehran, Iran, 2020.

[27] Ministry of Energy. An Overview of 30 Years of the Country's Energy Statistics; Ministry of Energy: Tehran, Iran, 2020.

[28] Ministry of Energy. Time Series for Iran's Energy Balances; Ministry of Energy: Tehran, Iran, 2020.

[29] Rezaei, T.; Takif, A.; Ghasemi, A. Feasibility study of gas hub formation using SWOT approach. Iran. J. Energy Econ. 2018, 8, 69-102.

[30] Sadik-Zada, E.R.; Gatto, A. Energy Security Pathways in South East Europe: Diversification of the Natural Gas Supplies, Energy Transition, and Energy Futures. In From Economic to Energy Transition. Energy, Climate and the Environment; Mišík, M., Oravcová, V., Eds.; Palgrave Macmillan: Cham, Switzerland, 2021.

[31] Hafezi, R.; Akhavan, A.N.; Pakseresht, S. Projecting plausible futures for Iranian oil and gas industries: Analyzing of historical strategies. J. Nat. Gas Sci. Eng. 2017, 39, 15-27.

[32] Azadi, P.; Nezam Sarmadi, A.; Shirvani, T. The Outlook for Natural Gas, Electricity, and Renewable Energy in Iran; The Stanford Iran 2040 Project, Working Paper No. 3; Stanford University: Stanford, CA, USA, 2017.

[33] Renewable Energy and Energy Efficiency Organization (SATBA). Annual Report on Renewable Energy and Employment-2018; SATBA: Tehran, Iran, 2020.

[34] Pishgar-Komleh, S.H.; Akram, A. Evaluation of wind energy potential for different turbine models based on the wind speed data of Zabol region, Iran. Sustain. Energy Technol. Assess. 2017, 22, 34-40.

[35] Fazelpour, F.; Markarian, E.; Soltani, N. Wind energy potential and economic assessment of four locations in Sistan and Balouchestan province in Iran. Renew. Energy 2017, 109, 646-667.

[36] Aryanpur, V.; Atabaki, M.S.; Marzband, M.; Siano, M.P.; Ghayoumi, K. An overview of energy planning in Iran and transition pathways towards sustainable electricity supply sector. Renew. Sustain. Energy Rev. 2019, 112, 58-74.

[37] Najafi, G.; Ghobadian, B. LLK1694-wind energy resources and development in Iran. Renew. Sustain. Energy Rev. 2011, 15, 27192728.

[38] Global Wind Energy Council. Annual Global Wind Report (2019); Global Wind Energy Council: Brussels, Belgium, 2020.

[39] Razavieh, A.; Sedaghat, A.; Ayodele, R.; Mostafaeipour, A. Worldwide wind energy status and the characteristics of wind energy in Iran, case study: The province of Sistan and Baluchestan. Int. J. Sustain. Energy 2017, 36, 103-123.

[40] Skandari Shabani, S.; Maki, S.V. Hydropower plants. In Proceedings of the 3rd International Conference on Science and Engineering, Istanbul, Turkey, 2 June 2016; Available online: https://civilica.com/doc/491476 (accessed on 25 June 2021).

[41] Manzoor, D.; Rahimi, A. Prioritization of power plants in Iran using multidisciplinary decision models. Iran. J. Energy Econ. 2015, 4, 191-215.

[42] Rezaei, R.; Ghofranfarid, M. Rural households' renewable energy usage intention in Iran: Extending the unified theory of acceptance and use of technology. Renew. Energy 2018, 122, 382-391.

[43] Jahangoshai Rezaee, M.; Yousefi, S.; Hayati, J. Root barriers management in development of renewable energy resources in Iran: An interpretative structural modeling approach. Energy Policy 2019, 129, 292-306.

[44] Pirasteh, G.; Ashrafizadeh, A.; Salehi Dezfuli, M.M. Energy policies and their impact on the development of renewable energy. In Proceedings of the Fifth Conference on Renewable, Clean and Efficient Energy, Tehran, Iran, 6 March 2013.

[45] Mistry of Energy. General Policies, Country's General Policies; Mistry of Energy: Tehran, Iran, 2000.

[46] Solaymani, S. A CO2 Emissions Assessment of the Green Economy in Iran. Greenh. Gases Sci. Technol. $2020,10,390-407$.

[47] Aghahosseini, A.; Bogdanov, D.; Ghorbani, N.; Breyer, C. Analysis of 100\% renewable energy for Iran in 2030: Integrating solar PV, wind energy and storage. Int. J. Environ. Sci. Technol. 2018, 15, 17-36. 
[48] Torabi, G.; Khoshnavaz, M.; Safari Karchani, A.; Ghadimi, A.A. Potential Assessment and Identification of Potential Points for Installation of Very Small Hydropower Plants in Lorestan Province; Niroo Research Institute: Tehran, Iran, 2009.

[49] Hajighafouri Bukani, N. Investigation of hydropower plants in Iran and some countries of the world. Mech. Eng. 2015, 103, 3646.

[50] Sovacool, B.K.; Walter, G. Major hydropower states, sustainable development, and energy security: Insights from a preliminary cross-comparative assessment. Energy 2018, 142, 1074-1082.

[51] Shahsavari, A.; Yazdi, F.T.; Yazdi, H.T. Potential of solar energy in Iran for carbon dioxide mitigation. Int. J. Environ. Sci. Technol. 2019, 16, 507-524.

[52] Dehghan, A.A. Status and potentials of renewable energies in Yazd Province-Iran. Renew. Sustain. Energy Rev. 2011, 15, 14911496.

[53] Sharbafian, N. Estimation of Technical and Economic Potential of Thermal Solar Energy in Iran: A Strategy for Sustainable Development of Solar Energy. Energy Econ. Stud. 2007, 4, 35-53.

[54] Gorgani Firouzjah, K. Assessment of small-scale solar PV systems in Iran: Regions priority, potentials and financial feasibility. Renew. Sustain. Energy Rev. 2018, 94, 267-274.

[55] Sansaniwal, S.K.; Sharma, V.; Mathur, J. Energy and exergy analyses of various typical solar energy applications: A comprehensive review. Renew. Sustain. Energy Rev. 2018, 82, 1576-1601.

[56] Badran, O.O. Study in industrial applications of solar energy and the range of its utilization in Jordan. Renew. Energy 2001, 24, 485-490.

[57] Gorjian, S.; Zadeh, B.N.; Eltrop, L.; Shamshiri, R.R.; Amanlou, Y. Solar photovoltaic power generation in Iran: Development, policies, and barriers. Renew. Sustain. Energy Rev. 2019, 106, 110-123.

[58] Edalati, E.; Ameri, M.; Iranmanesh, M.; Sadeghi, Z. Solar photovoltaic power plants in five top oil-producing countries in Middle East: A case study in Iran. Renew. Sustain. Energy Rev. 2017, 69, 1271-1280.

[59] Wyman, C.E.; Goodman, B.J. Biotechnology for production of fuels, chemicals, and materials from biomass. Appl. Biochem. Biotechnol. 1993, 39, 41.

[60] SATBA. Report 4: Biomass Energy 1; SATBA: Tehran, Iran, 2005. Available online: http://www.dres-isf.ir/home/phocadownload/\%D8\%B2\%DB\%8C\%D8\%B3\%D8\%AA\%20\%D8\%AA\%D9\%88\%D8\%AF\%D9\%87.pdf (accessed on 25 June 2021).

[61] Ministry of Agriculture Jihad. Annual Report 2019; Ministry of Agriculture Jihad: Tehran, Iran, 2019.

[62] Mohammadi Moghanaki, M.; Ghobadian, B.; Janzadeh Gulogah, R.; Najafi, G.H. Feasibility study of the use of agricultural waste in the simultaneous production of electricity and heat in Iran. In Proceedings of the Second International Conference on Recycled Waste and Biomass Management, Tehran, Iran, 14-17 November 2012.

[63] Samadi, S.H.; Ghobadian, B.; Nosrati, M. Prediction and estimation of biomass energy from agricultural residues using air gasification technology in Iran. Renew. Energy 2020, 149, 1077-1091.

[64] Rezaei, M.; Mostafaeipour, A.; Qolipour, M.; Tavakkoli Moghaddam, R. Investigation of the optimal location design of a hybrid wind-solar plant: A case study. Int. J. Hydrog. Energy 2018, 43, 100-114.

[65] Solaymani, S. A demand-side assessment of sustainable energy security in Iran. Int. J. Energy Water Resour. 2020, 4, 307-320.

[66] Abyaz, A.; Najafi, Z.; Afra, E. Evaluation of biofuel production infrastructures from sugarcane bagasse in Iran. In Proceedings of the National Conference on Wood and Lignocellulose Products, Gonbad-e Kavus, Iran, 8 March 2016.

[67] Hajinezhad, A.; Katooli, M.H. Study on nutritional values of a novel plant in Iran-Nowruzak- and its application in producing biofuels. Sustain. Chem. Pharm. 2018, 10, 112-117.

[68] Kheybari, S.; Rezaie, F.M. Selection of biogas, solar, and wind power plants' locations: An MCDA approach. J. Supply Chain. Manag. 2020, 1, 45-71.

[69] Solaymani, S. Energy subsidy reform evaluation research-Reviews in Iran. Greenh. Gases Sci. Technol. 2021.

[70] Ghobadian, B. Liquid biofuels potential and outlook in Iran. Renew. Sustain. Energy Rev. 2012, 16, 4379-4384.

[71] Madadi, M.; Aqleem Abbas, Z. Green biodiesel production potential from oil seeds in Iran. Int. J. Life Sci. Sci. Res. 2017, 3, 895904.

[72] Sepaskhah, A. Sustainable production of bioethanol in relation to soil and water resources in Iran. Strateg. Res. Agric. Sci. Nat. Resour. 2017, 2, 24-29.

[73] Rashidikia, M.; Moradi, M. Biofuel for the optimal use of agricultural waste and its role in sustainable development. Stud. Nat. Resour. Environ. Agric. 2015, 2, 17-18.

[74] Yousefi, H.; Roumi, S.; Ármannsson, H.; Noorollahi, Y. Cascading uses of geothermal energy for a sustainable energy supply for Meshkinshahr City, Northwest, Iran. Geothermics 2019, 79, 152-163.

[75] Roumi, S.; Yousefi, H.; Noorollahi, Y.; Bekhrad, K.; Zarrouk, S.J. Direct Applications of Geothermal Energy; Economic and Environmental Assessment: Meshkin-Shahr, Iran. In Proceedings of the 42nd Workshop on Geothermal Reservoir Engineering, Stanford, CA, USA, 13-15 February 2017.

[76] Pourkiaei, S.M.; Pourfayaz, F.; Shirmohammadi, R.; Moosavi, S.; Khalilpoor, N. Potential, current status, and applications of renewable energy in energy sector of Iran: A review. Renew. Energy Res. Appl. 2020.

[77] Noorollahi, Y.; Shabbir, M.S.; Siddiqi, A.F.; Ilyashenko, L.K.; Ahmadi, E. Review of two decade geothermal energy development in Iran, benefits, challenges, and future policy. Geothermics 2019, 77, 257-266. 
[78] Khoshnevis, S.; Shakouri, B. Renewable energy, nonrenewable energy consumption, and economic growth. Energy Sources Part B Econ. Plan. Policy 2017, 12, 1038-1045.

[79] Li, Y.; Solaymani, S. Energy consumption, technology innovation and economic growth nexuses in Malaysian. Energy 2021, 232, 121040.

[80] Razmi, S.F.; Bajgiran, B.R.; Behname, M.; Salari, T.E.; Razmi, S.M.J. The relationship of renewable energy consumption to stock market development and economic growth in Iran. Renew. Energy 2020, 145, 2019-2024.

[81] Salmanzadeh, M.N.; Fatemi, G.S.M.T. The causal relationship among electricity consumption, economic growth and capital stock in Iran. J. Policy Modeling 2019, 41, 1230-1256.

[82] Ahssein Amran, Y.H.; Mugahed Amran, Y.H.; Alyousef, R.; Alabduljabbar, H. Renewable and sustainable energy production in Saudi Arabia according to Saudi Vision 2030; Current status and future prospects. J. Clean. Prod. 2020, $247,119602$.

[83] Salam, M.A.; Khan, S.A. Transition towards sustainable energy production-A review of the progress for solar energy in Saudi Arabia. Energy Explor. Exploit. 2018, 36, 3-27.

[84] Mohammed, O.H. Optimal Hybridisation of a Renewable System to Fulfill Residential Electrical Load: In Mosul, Iraq. In Proceedings of the 2018 Third Scientific Conference of Electrical Engineering (SCEE), Baghdad, Iraq, 19-20 December 2018.

[85] Marchenko, O.V.; Solomin, S.V. Efficiency of Hybrid Renewable Energy Systems in Russia. Int. J. Renew. Energy Res. 2017, 7, 1561-1569.

[86] Norouzi, N.; Zarazua de Rubens, G.; Choupanpiesheh, S.; Enevoldsen, P. When pandemics impact economies and climate change: Exploring the impacts of COVID-19 on oil and electricity demand in China. Energy Research \& Social Science 2020, 68, 101654, https://doi.org/10.1016/j.erss.2020.101654.

[87] Norouzi, N.; Kalantari, G. The sun food-water-energy nexus governance model a case study for Iran, Water-Energy Nexus 2020, 3, 72-80, https://doi.org/10.1016/j.wen.2020.05.005

[88] Fani, M.; Norouzi, N. Using Social and Economic Indicators for Modeling, Sensitivity Analysis and Forecasting the Gasoline Demand in the Transportation Sector An ANN Approach in case study for Tehran metropolis. Iranian Journal of Energy International energy agency, 2019.

[89] Norouzi, N.; Fani, M.; Karami Ziarani, Z. The Fall of oil age: A scenario planning approach over the last peak oil of human history by 2040, petroleum science and engineering 2020, 188, 106827. 10.1016/j.petrol.2019.106827 